\title{
Pathological tau drives ectopic nuclear speckle scaffold protein SRRM2 accumulation in neuron cytoplasm in Alzheimer's disease
}

\author{
Pamela J. McMillan ${ }^{1,2}$, Timothy J. Strovas ${ }^{1}$, Misa Baum ${ }^{1}$, Brooke K. Mitchell ${ }^{1}$, Randall J. Eck ${ }^{3,5}$, Nzinga Hendricks ${ }^{1}$, \\ Jeanna M. Wheeler ${ }^{1}$, Caitlin S. Latimer ${ }^{4}$, C. Dirk Keene ${ }^{3,4}$ and Brian C. Kraemer ${ }^{1,2,3,4,5^{*}}$ (D)
}

\begin{abstract}
Several conserved nuclear RNA binding proteins (sut-1, sut-2, and parn-2) control tau aggregation and toxicity in C. elegans, mice, and human cells. MSUT2 protein normally resides in nuclear speckles, membraneless organelles composed of phase-separated RNAs and RNA-binding proteins that mediate critical steps in mRNA processing including mRNA splicing. We used human pathological tissue and transgenic mice to identify Alzheimer's disease-specific cellular changes related to nuclear speckles. We observed that nuclear speckle constituent scaffold protein SRRM2 is mislocalized and accumulates in cytoplasmic lesions in AD brain tissue. Furthermore, progression of tauopathy in transgenic mice is accompanied by increasing mislocalization of SRRM2 from the neuronal nucleus to the soma. In AD brain tissue, SRRM2 mislocalization associates with increased severity of pathological tau deposition. These findings suggest potential mechanisms by which pathological tau impacts nuclear speckle function in diverse organisms ranging from C. elegans to mice to humans. Future translational studies aimed at restoring nuclear speckle homeostasis may provide novel candidate therapeutic targets for pharmacological intervention.
\end{abstract}

Keywords: Nuclear speckles, Alzheimer's disease, MSUT2, PABPN1, Tau, MapT tauopathy PS19, SRRM2, SC-35, ZC3H14

\section{Introduction}

Amyloid beta $(A \beta)$ plaques and neurofibrillary tangles (NFTs) containing aggregates of hyperphosphorylated tau represent the diagnostic pathological lesions present in Alzheimer's disease (AD) brains. The mechanism of interaction between $A \beta$ plaques and NFTs remains incompletely understood, but both contribute to neurodegeneration in $\mathrm{AD}$. The discovery of mutations causing FTLD-tau in the human gene encoding tau protein has demonstrated amyloid independent tau neurotoxicity [1-3] and tangles, rather than plaques, correlate most closely with the severity of dementia in AD [4]. These

\footnotetext{
*Correspondence: kraemerb@u.washington.edu

${ }^{1}$ Geriatrics Research Education and Clinical Center, Veterans Affairs Puget

Sound Health Care System, S182, 1660 South Columbian Way, Seattle, WA 98108, USA

Full list of author information is available at the end of the article
}

observations support the need for further exploration of the mechanistic underpinnings of both $A \beta$ - and taumediated neurodegeneration in AD. Here we focus on disease mechanisms relating pathological tau to nuclear dysfunction.

Recent work has implicated nuclear dysfunction of RNA-binding proteins as a driver of neurodegeneration in model organisms and cellular systems [5-8]. RNA acts as a potent initiator of tau aggregation in vitro and can decorate fibrillar tau after aggregation [9-11]. Most recently, tau has been shown to form aggregates with an RNA protein assembly in some cellular contexts [7]. The recruitment of RNA to tau aggregates may drive splicing defects or disrupt other nuclear functions related to RNA [5-7, 12]. These observations suggest the possibility of tauopathy-driven RNA-mediated cellular dysfunction, but these phenomena have not been investigated in the original author(s) and the source, provide a link to the Creative Commons licence, and indicate if changes were made. The images or other third party material in this article are included in the article's Creative Commons licence, unless indicated otherwise in a credit line to the material. If material is not included in the article's Creative Commons licence and your intended use is not permitted by statutory regulation or exceeds the permitted use, you will need to obtain permission directly from the copyright holder. To view a copy of this licence, visit http://creativecommons.org/licenses/by/4.0/. The Creative Commons Public Domain Dedication waiver (http://creativeco mmons.org/publicdomain/zero/1.0/) applies to the data made available in this article, unless otherwise stated in a credit line to the data. 
context of AD pathology. Here, we begin to address the role of RNA binding protein involvement with pathological tau in $\mathrm{AD}$, guided by findings from molecular genetic investigations in model systems.

In our previous genetic studies of tauopathy in C. elegans, we identified multiple genes whose loss of function suppress tauopathy neurodegenerative phenotypes (suppressor of tauopathy or sut genes). The largest group of sut genes isolated encode proteins residing in nuclear speckles, which suggests modulating nuclear speckle function can ameliorate tauopathy. Conserved sut genes may also play a role in tau mediated neurodegeneration in mammals. The first tauopathy suppressor isolated, sut1, exhibits strong suppression of tauopathy phenotypes; SUT-1 protein localizes to nuclear speckles [13] and is thought to mediate spliceosome recycling [14]. The parn2 gene is another recently isolated partial tau suppressor gene encoding a protein known to reside in nuclear speckles with poly(A) RNase activity [15].

To determine whether conserved sut genes may play a role in tau mediated neurodegeneration in mammals, we have explored the translational potential of sut-2. We first identified sut-2 as a suppressor of tau-induced neurodegenerative defects in C. elegans [16]. The sut2 gene encodes a zinc finger protein with a single conserved homolog in diverse species ranging from yeast to humans. The mammalian SUT-2 protein (MSUT2) binds to RNA and localizes to nuclear speckles, membraneless organelles coordinating mRNA processing in the nucleus $[17,18]$. Knockout of the MSUT2 gene in mice results in animals that develop appropriately and appear healthy, live a normal lifespan, and exhibit normal neurological function including learning and memory [19]. We have shown that MSUT2 KO in mice can suppress tauopathy phenotypes in a transgenic mouse model expressing human tau protein. PS19 tau transgenic mice exhibit early stages of tauopathy by 3 months of age that progress to neurofibrillary degeneration by 8 months. These mice exhibit pathological tau and cognitive dysfunction resembling the changes observed in human $\mathrm{AD}$ patients or those with other tauopathy disorders. When combined with the PS19 transgene, MSUT2 gene knockout ameliorates a variety of pathological tau lesions. For instance, MSUT2 KO decreases accumulation of phosphorylated tau (pTau) lesions as represented by immunostaining with AT180, an early marker of pathological tau [20]. Likewise, MSUT2 KO decreased pre-tangle conformations of tau, critical for the eventual formation of mature NFTs [21]. The deposition of tangles is accompanied by obvious neurodegeneration in PS19 Tg mice and MSUT2 $\mathrm{KO}$ reduces the tau-mediated loss of neurons in the hippocampus [19]. The amelioration of neurodegeneration is also accompanied by a reduction in astrocytosis as indicated by GFAP staining [19]. We also found MSUT2 $\mathrm{KO}$ mice exhibit robust amelioration of tauopathy-related behavioral phenotypes, including a restoration of spatial memory function as detected by the Barnes maze test.

Given the above findings demonstrating MSUT2 involvement in determining susceptibility to pathological tau, combined with its role as a nuclear speckle-localized RNA-binding protein, we have begun to explore the role of RNA-binding protein-mediated pathological consequences of tauopathy in $\mathrm{AD}$. In this study, we investigated another nuclear speckle protein, SRRM2, which is a core nuclear speckle scaffold protein required for the formation of nuclear speckles. Recent studies indicate SRRM2 abnormality in AD cellular and animal models [7, 22]. Guided by findings from molecular genetic investigations in model systems, the current study examines the impact of pathological tau on SRRM2 protein in the brains of AD patients and mouse models of tauopathy.

\section{Materials and methods \\ Brain tissue from $A D$ and control cases}

Samples of postmortem brain tissue were obtained from the University of Washington (UW) Alzheimer's Disease Research Center (ADRC) and the Adult Changes in Thought (ACT) Study via the UW BioRepository and Integrated Neuropathology Laboratory. Informed consent for research brain donation was obtained from the legal next of kin according to protocols approved by the UW Institutional Review Board. AD cases $(n=29)$ were selected based on a clinical diagnosis of dementia and autopsy-confirmed AD neuropathologic change (ADNC) sufficient to explain dementia. Control postmortem brain samples $(n=7)$ were from age-matched cognitively normal research participants with autopsy-confirmed absent-low levels of ADNC. Donor brains were fixed in $10 \%$ neutral buffered formalin for at least two weeks, coronally sliced, and samples of prefrontal cortex, hippocampus, amygdala and cerebellum processed and embedded in paraffin, and sectioned at 5 micron thickness according to routine protocols. Tissue was subjected to histological and neuropathological analysis as described below (Table 1).

\section{Mouse experiments}

All mouse experiments were reviewed and approved by the VA Puget Sound Health Care System Institutional Animal Care and Use Committee (IACUC) and conducted in an American Association for Accreditation of Laboratory Animal Care (AAALAC)-accredited animal research facility. The PS19 tau transgenic mouse model expressing human P301S mutant human tau was used in this study. This mouse model is well characterized and has a highly progressive tauopathy related phenotype. 
In addition, a milder mouse model of tauopathy driven by wild type human tau expression (Tau4Rtg2652) was also examined. This mouse line exhibits early-stage tau pathology, including phosphorylated tau, but not neurofibrillary degeneration [23]. PS19 mice (15 three month, 7 at seven months of age and 16 at nine months of age), Tau4Rtg2652 mice (8 at 4 months of age) and WT mice ( 5 at nine months of age) were anesthetized and fixed by transcardial perfusion with $4 \%$ paraformaldehyde. Brains were removed and paraffin embedded for sectioning.
Coronal sections (9 microns) were prepared and stored at $4{ }^{\circ} \mathrm{C}$ until use.

\section{Tissue Immunohistochemistry and staining}

Human and mouse brain sections were deparaffinized, rehydrated through alcohols, and processed through antigen retrieval steps consisting of heat pretreatment in citrate buffer by either microwave or autoclave per antibody-specific protocols. Sections were treated for endogenous peroxidases with $3 \%$ hydrogen peroxide in

Table 1 Case details

\begin{tabular}{|c|c|c|c|c|c|c|c|c|}
\hline Case \# & Dx (NP verified & Age at death & Sex & Age at onset & $\begin{array}{l}\text { Duration } \\
\text { (years) }\end{array}$ & PMI (hrs) & $\begin{array}{l}\text { NIA-AA B } \\
\text { score }\end{array}$ & $\begin{array}{l}\text { NIA-AA } \\
\text { C score }\end{array}$ \\
\hline 1 & $A D$ & 76 & M & 65 & 11 & $4: 30$ & 3 & 3 \\
\hline 2 & $A D$ & 82 & $\mathrm{~F}$ & 55 & 27 & $8: 00$ & 3 & 3 \\
\hline 3 & $A D$ & 60 & $\mathrm{~F}$ & 54 & 6 & $7: 30$ & 2 & 2 \\
\hline 4 & $A D$ & 82 & M & 76 & 6 & $8: 00$ & 2 & 3 \\
\hline 5 & $A D$ & 80 & $\mathrm{~F}$ & 69 & 11 & $6: 00$ & 3 & 3 \\
\hline 6 & $A D$ & 71 & $\mathrm{~F}$ & 60 & 11 & $5: 00$ & 3 & 3 \\
\hline 7 & $A D$ & 81 & $\mathrm{~F}$ & 71 & 10 & $4: 00$ & 3 & 3 \\
\hline 8 & $A D$ & 70 & $\mathrm{~F}$ & 62 & 8 & $5: 00$ & 3 & 3 \\
\hline 9 & $A D$ & 68 & M & 58 & 10 & $9: 25$ & 3 & 3 \\
\hline 10 & $A D$ & 77 & M & 57 & 20 & $7: 25$ & 3 & 3 \\
\hline 11 & $A D$ & 84 & $\mathrm{~F}$ & 76 & 8 & $4: 47$ & 3 & 3 \\
\hline 12 & $A D$ & 93 & $\mathrm{~F}$ & 84 & 9 & $6: 30$ & 3 & 1 \\
\hline 13 & $A D$ & 62 & M & 55 & 7 & $4: 32$ & 3 & 3 \\
\hline 14 & $A D$ & 88 & $\mathrm{~F}$ & 77 & 11 & $5: 40$ & 3 & 3 \\
\hline 15 & $A D$ & 78 & $M$ & 72 & 6 & $7: 00$ & 3 & 3 \\
\hline 16 & $A D$ & 86 & $\mathrm{~F}$ & 76 & 10 & $8: 32$ & 3 & 3 \\
\hline 17 & $A D$ & 75 & $M$ & 64 & 11 & $4: 30$ & 3 & 3 \\
\hline 18 & $A D$ & 90 & $\mathrm{~F}$ & 76 & 14 & $6: 23$ & 3 & 3 \\
\hline 19 & $A D$ & 89 & $\mathrm{~F}$ & 82 & 7 & $5: 23$ & 3 & 2 \\
\hline 20 & $A D$ & 77 & $M$ & 71 & 6 & $6: 32$ & 3 & 3 \\
\hline 21 & $A D$ & 78 & $\mathrm{~F}$ & 69 & 9 & $2: 20$ & 3 & 2 \\
\hline 22 & $A D$ & 94 & $M$ & 91 & 3 & $3: 05$ & 3 & 3 \\
\hline 23 & $A D$ & 86 & $M$ & 80 & 6 & $2: 40$ & 3 & 3 \\
\hline 24 & $A D$ & 77 & $M$ & 63 & 14 & $5: 20$ & 2 & 3 \\
\hline 25 & $A D$ & 100 & $\mathrm{~F}$ & 82 & 18 & $3: 08$ & 3 & 2 \\
\hline 26 & $A D$ & 91 & $M$ & 82 & 9 & $7: 00$ & 3 & 2 \\
\hline 27 & $A D$ & 94 & $M$ & 82 & 12 & $4: 25$ & 3 & 3 \\
\hline 28 & $A D$ & 86 & $M$ & 81 & 5 & $4: 25$ & 3 & 3 \\
\hline 29 & $A D$ & 89 & $M$ & 86 & 3 & $6: 25$ & 3 & 3 \\
\hline 30 & CNT & 92 & $M$ & NA & NA & $4: 20$ & 1 & 1 \\
\hline 31 & CNT & 81 & $M$ & NA & NA & $5: 45$ & 1 & 1 \\
\hline 32 & CNT & 78 & $\mathrm{~F}$ & NA & NA & $6: 00$ & 1 & 1 \\
\hline 33 & CNT & 95 & $M$ & NA & NA & $4: 00$ & 1 & 1 \\
\hline 34 & CNT & 91 & $\mathrm{~F}$ & NA & NA & $6: 00$ & 2 & 1 \\
\hline 35 & CNT & 78 & $M$ & NA & NA & $5: 35$ & 2 & 1 \\
\hline 36 & CNT & 79 & $\mathrm{~F}$ & NA & NA & $7: 00$ & 1 & 1 \\
\hline
\end{tabular}


PBS (pH 7.4), blocked in 5\% non-fat milk in PBS, and incubated with primary antibodies overnight at $4{ }^{\circ} \mathrm{C}$ (see Table 2). Biotinylated secondary antibody was applied for $45 \mathrm{~min}$ at room temperature. Finally, sections were incubated in an avidin-biotin complex with streptavidin-HRP (Vector's Vectastain Elite ABC-HRP kit, Burlingame, $\mathrm{CA}$ ) and the reaction product was visualized with $0.05 \%$ diaminobenzidine (DAB)/0.01\% hydrogen peroxide in PBS. Negative controls consisted of full protocol except primary antibody. The presence of neurofibrillary tangles was assessed by Gallyas silver staining using standard methods. Digital images were obtained using a Leica DM6 microscope with a DFC 7000 digital camera (Leica Microsystems, Wetzlar, Germany) and imported into Adobe Photoshop (Adobe Inc, San Jose, CA).

\section{Statistical analysis}

For quantitation in human tissue, immunostained sections were analyzed using the computer image analysis system MicroComputer Imaging Device (MCID; Imaging Research, St. Catherines, Ontario, Canada) and blinded assessment of optical density measurements were obtained relative to the proportional area for AT180 and NeuN immunostaining in frontal cortex grey matter (three separate readings per case) as previously described [19]. For quantitation in mouse brain tissue, the number of neurons with cytoplasmic pSRRM2 inclusions were manually counted across the entire section (two sections per animal). Data were averaged and are represented as means \pm SEM. A two-tailed Student's t test was used to assess differences in staining intensity between experimental groups. Statistical analysis and graphing was performed using the Prism V8.3 software package (GraphPad).

\section{Immunofluorescence microscopy, co-localization, and proximity ligation studies}

Human frontal cortex sections were deparaffinized followed by antigen retrieval as described above. Sections were permeabilized in $0.2 \%$ Triton X-100 in PBS, blocked with $2 \%$ goat serum in PBS and incubated overnight at $4{ }^{\circ} \mathrm{C}$ with primary antibodies to pSRRM2 (mouse mAb clone SC-35, [24] and pS422 (rabbit mAb clone EPR2866) or DAKO anti-tau (rabbit polyclonal anti-tau). For double label immunofluorescence, secondary antibodies AlexaFluor 488 goat anti-rabbit and AlexaFluor 647 goat antimouse secondary antibodies (ThermoFisher, Waltham, MA) were applied for $45 \mathrm{~min}$ at room temperature and sections were counterstained with 300 nM DAPI before mounting with ProLong Gold Antifade. Images were obtained on a DeltaVision Elite microscope (Cytava Lifesciences, Marlborough, MA) using a 100X oil immersion objective and colocalization analysis was performed with SoftwoRx 6.0 Beta software (Cytiva).

Proximity Ligation assays were performed using Duolink PLA technology as recommended by the manufacturer (Sigma-Aldrich Catalog\# DUO92101,St. Louis, MO) using sections prepared through primary antibody incubation as described above. Human brain samples assayed for pSRRM2 and pS422 colocalization were imaged on a Nikon A1R confocal microscope using a $100 \times$ oil immersion objective (Nikon USA, Melville, NY).

\section{Results}

\section{Phosphorylated nuclear speckle scaffold protein SRRM2 becomes mislocalized in Alzheimer's disease}

Since sut-2 and its homolog MSUT2 enable the development of tau pathology and appear to reside in nuclear speckles within the nuclei of neurons [13, 16, 25], we hypothesized that nuclear speckle function may play an important role in the genesis or progression of pathological tau. To further investigate the involvement of nuclear speckles in neurodegenerative tauopathy, we immunostained brain sections from AD cases for the canonical nuclear speckle marker monoclonal antibody (mAb) clone SC-35. The mAb SC-35 was originally raised against purified human spliceosomes and has recently been conclusively demonstrated to recognize a phosphorylated epitope of human SRRM2 (pSRRM2) protein $[24,26]$. SRRM2 protein plays a key role in mRNA splicing as a nuclear matrix protein $[27,28]$ and is a critical nuclear speckle co-scaffolding protein with SON protein [26]. Immunostaining with mAb SC-35 demonstrates a clear disruption of the normal canonical nuclear speckle staining pattern in the frontal cortex of a majority of AD cases, but not in age-matched controls (Fig. 1). The striking mis-localization of SRRM2 appears to be a relocalization of pSRRM2 protein from the nuclear speckles within neuronal nuclei to the soma, with pSRRM2 accumulating in the cytoplasm. This abnormal pSRRM2 staining pattern occurs in the frontal cortex in 20 out of 29 AD cases. Furthermore, this cytoplasmic distribution of pSRRM2 was detected in all 29 AD cases in the hippocampus and amygdala, regions known to accumulate abundant tau pathology at an earlier stage in the disease process. In contrast, we did not observe pSRRM2 mislocalization in the cerebellum, a brain region generally spared from neurodegeneration and pathological tau in $\mathrm{AD}$; rather we observed a normal pattern clearly marking nuclear speckles. Taken together, the pattern of neurons exhibiting pSRRM2 mis-localization parallels the pattern of pathological neurofibrillary tangle deposition in $\mathrm{AD}$ brain. 

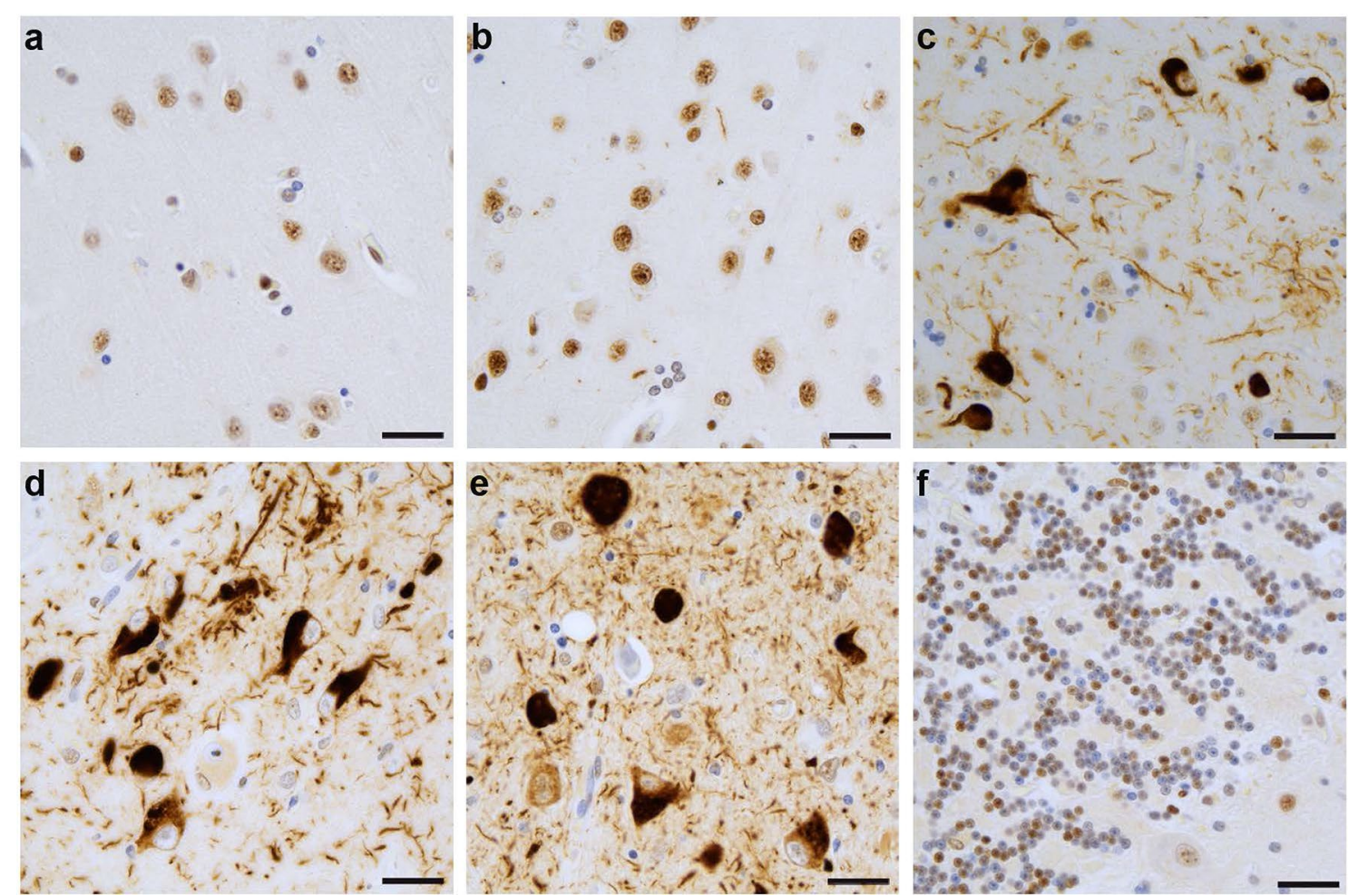

Fig. 1 Derangement of nuclear speckle marker pSRRM2 (ab SC-35) in AD. Immunohistochemistry using a pSRRM2 recognizing antibody raised against purified human spliceosomes (clone SC-35, see Table 2). Human pSRRM2 stains nuclear speckles within neurons in the frontal cortex of the normal adult human brain (a). A subset of AD donors (30\%) also exhibit normal nuclear speckle staining in cortical neurons (b), however, the majority of AD donors (72\%) exhibit striking mis-localization of pSRRM2 to the cytoplasm in neurons in the frontal cortex (c). Additionally, all AD donors exhibited mis-localization of pSRRM2 in the hippocampus (d) and amygdala (e), brain regions where tauopathy occurs earlier in disease progression. AD donors with aberrant cytoplasmic PSRRM2 in tauopathy rich regions showed normal nuclear pSRRM2 distribution in cerebellar neurons (f), which do not typically exhibit any tau pathology. Scale bars, $50 \mu \mathrm{m}$

\section{Tau pathology drives mis-localization and pathological deposition of phospho-SRRM2 into tau lesions}

Because pSRRM2 mis-localization occurs in the same brain regions as neurofibrillary degeneration, we hypothesized that pathological tau deposition provokes ectopic pSRRM2 accumulation in the neuronal soma. To test this idea, we examined the pattern of pSRRM2 staining in the brains of PS19 tau transgenic mice. This well characterized mouse model of tauopathy exhibits high level expression of the FTLD P301S mutant human tau in degenerating neurons [23]. While SRRM2 is well conserved between humans and mice [29], phosphorylation of SRRM2 is complex with potential variation between mice and humans $[22,26]$. In aged PS19 mice following onset of neurofibrillary tangle deposition, pSRRM2 mis-localization becomes evident and is similar to the aberrant cytoplasmic accumulation we observed in $\mathrm{AD}$ brain (Fig. $2 \mathrm{a}-\mathrm{f}, \mathrm{h}$ ). In non-Tg mice, $\mathrm{mAb}$ clone $\mathrm{SC}-35$ does not detect any pSRRM2 protein (Fig. 2 g) and in 3-monthold PS19 mice pSRRM2 appears as diffuse mild immunoreactivity in the cytoplasm (Fig. 2a) and there are no tangles (Fig. 2b). We find robust accumulation of cytoplasmically mis-localized pSRRM2 (Fig. 2c) in a subset of neurons and detect sparse NFTs in 7-monthold PS19 mice (Fig. 2d). By nine months of age, PS19 mice exhibit significant pSRRM2 cytoplasmic accumulation in a substantial fraction of neurons in these same regions (Fig. 2e) and have accumulated substantial hippocampal and cortical NFTs (Fig. 2f) and begun to exhibit frank neurodegeneration. To validate these findings in a mouse model of tauopathy driven by wild type human tau expression, we examined pSRRM2 accumulation in the Tau4Rtg2652 mouse line, a model with early stage tau pathology, including phosphorylated tau, but without neurofibrillary degeneration. The Tau4Rtg2652 mice exhibit a milder but disrupted nuclear speckle staining pattern for pSRRM2 (Additional file 1: Fig S1). Because expression of the tau transgene drives the primary insult in tau transgenic mice, these findings suggest that pSRRM2 mis-localization to the cytoplasm occurs in neurons as a result of 
Table 2 Antibodies

\begin{tabular}{|c|c|c|c|c|c|}
\hline Antigen & Clone/product name & Dilution & Host species & Source & Catalog \# \\
\hline pSRRM2 & SC-35 & $1: 200$ & Mouse & SigmaAldrich & S4045 \\
\hline $\begin{array}{l}\text { pTau } \\
\text { Thr231 }\end{array}$ & AT180 & $1: 200$ & Mouse & ThermoScientific (Rockford, IL, USA) & MN1040 \\
\hline NeuN & A60 & $1: 400$ & mouse & Millipore & MAB377 \\
\hline Tau (Total) & SP70 pAb & $1: 1,000$ & Rabbit & $\begin{array}{l}\text { Rockland Immunochemicals Inc. (Limerick, } \\
\text { PA, USA) }\end{array}$ & 200-C01-B33 \\
\hline pTau Ser202 & CP13 mAb & $1: 500$ & Mouse & \multirow{2}{*}{$\begin{array}{l}\text { Peter Davies (Litwin-Zucker Research Center } \\
\text { for the Study of Alzheimer's Disease, The } \\
\text { Feinstein Institute of Medical Research, } \\
\text { Northwell Health, Manhasset, NY, USA) }\end{array}$} & \multirow[t]{2}{*}{ N/A } \\
\hline pTau Ser396/Ser404 & PHF-1 mAb & $1: 2,000$ & Mouse & & \\
\hline $\begin{array}{l}\text { pTau } \\
\text { Ser422 }\end{array}$ & EPR2866 mAb & $1: 500$ & Rabbit & Abcam (Cambridge, UK) & $a b 79415$ \\
\hline pTau Thr181 & AT270 mAb & $1: 15,000$ & Mouse & ThermoFisher Scientific (Waltham, MA, USA) & MN1050 \\
\hline Tau (Total) & K9JA (DAKO) pAb & $1: 250$ & Rabbit & $\begin{array}{l}\text { Agilent Technologies, Inc. (Santa Clara, CA, } \\
\text { USA) }\end{array}$ & A002401-2 \\
\hline $2^{\circ} \mathrm{Ab}$ Mouse & Horseradish Peroxidase a-Ms lgG $(H+L)$ & $1: 5,000$ & Goat & $\begin{array}{l}\text { Jackson Immunoresearch (West Grove, PA, } \\
\text { USA) }\end{array}$ & $115-035-146$ \\
\hline $2^{\circ} \mathrm{Ab}$ Rabbit & Horseradish Peroxidase a-Rb lgG $(H+L)$ & $1: 5,000$ & Goat & $\begin{array}{l}\text { Jackson Immunoresearch (West Grove, PA, } \\
\text { USA) }\end{array}$ & $111-035-144$ \\
\hline $2^{\circ} \mathrm{Ab}$ Mouse & Alexa Fluor ${ }^{\circledR} 568$ Goat a-Ms lgG $(\mathrm{H}+\mathrm{L})$ & $1: 1,000$ & Goat & Invitrogen (Carlsbad, CA, USA) & A-11004 \\
\hline $2^{\circ} \mathrm{Ab}$ Rabbit & Alexa Fluor ${ }^{\circledR} 647$ Goat a-Rb lgG $(H+L)$ & $1: 1,000$ & Goat & Invitrogen (Carlsbad, CA, USA) & $A-21245$ \\
\hline
\end{tabular}

pathological tau accumulation leading to neurodegeneration accompanied by mis-localization of pSRRM2. Further, these data suggest a hypothesis where cytoplasmic pSRRM2 marks a new subtype of neuropathological lesion associated with pathological tau in AD.

\section{SRRM2 + lesions co-localize with pathological tau in the cytoplasm and pSRRM2 becomes depleted from the nucleus}

To test the hypothesis that pSRRM2 + lesions overlap with pathological tau, we conducted co-immunofluorescent staining with antibodies against tau and pSRRM2 to fluorescently label pSRRM2+ and $\mathrm{Tau}+$ deposits in AD cases. From our co-labeling studies, we observe no obvious co-localization between SC-35 staining of pSRRM2 and pTau in cognitively normal controls (Fig. 3a). However, we observe strong co-localization between pSRRM2 and pTau in AD cases, with Pearson coefficient of colocalization (PCC) of 0.99 (Fig. 3b). In addition, pSRRM2 becomes depleted from the nucleus in cases with cytoplasmic pSRRM + deposits both in tangle bearing and nontangle bearing neurons. Further we demonstrated by proximity ligation assay that the tau positive lesions remain in close proximity to pSRRM2 + lesions localized in the cytoplasm of cortical neurons predominantly in $\mathrm{AD}$ patient brains but not age matched control brains (Fig. 3c).

\section{SRRM2 mis-localization overlaps with MSUT2 depletion in $A D$}

We previously showed that the nuclear speckle protein MSUT2 and its binding partner PABPN1 reciprocally influence vulnerability to tauopathy, and both become depleted in more severe AD cases [19]. To assess the interaction between cytoplasmic accumulation of pSRRM2 and MSUT2 in AD, we immunostained the frontal cortex of our AD cohort for MSUT2 (Table 3). All AD cases with predominately nuclear pSRRM2 $(n=9)$ had intact MSUT2 protein levels and milder tauopathy. In contrast, of our $18 \mathrm{AD}$ cases with substantial pSRRM2 cytoplasmic accumulation in the frontal cortex, 14 (78\%) had depleted MSUT2 and 17 (94\%) exhibited robust or moderate phospho-tau pathology. These data support the idea that MSUT2 depletion contributes to PSRRM2/ Tau+co-pathology in AD and suggest nuclear speckle disruption occurs as a cellular feature of AD.

\section{Pathological accumulation of cytoplasmic PSRRM2} coincides with tauopathy severity in Alzheimer's Disease Given the potential involvement of nuclear speckle components in tauopathy and co-deposition of pSRRM2 with tau in pathological lesions in $\mathrm{AD}$, we examined the relationship between mis-localization of pSRRM2 and disease severity. First, we tested for associations between pSRRM2 and clinical AD manifestation by comparing age at onset and the presence of PSRRM2 within the neuronal 

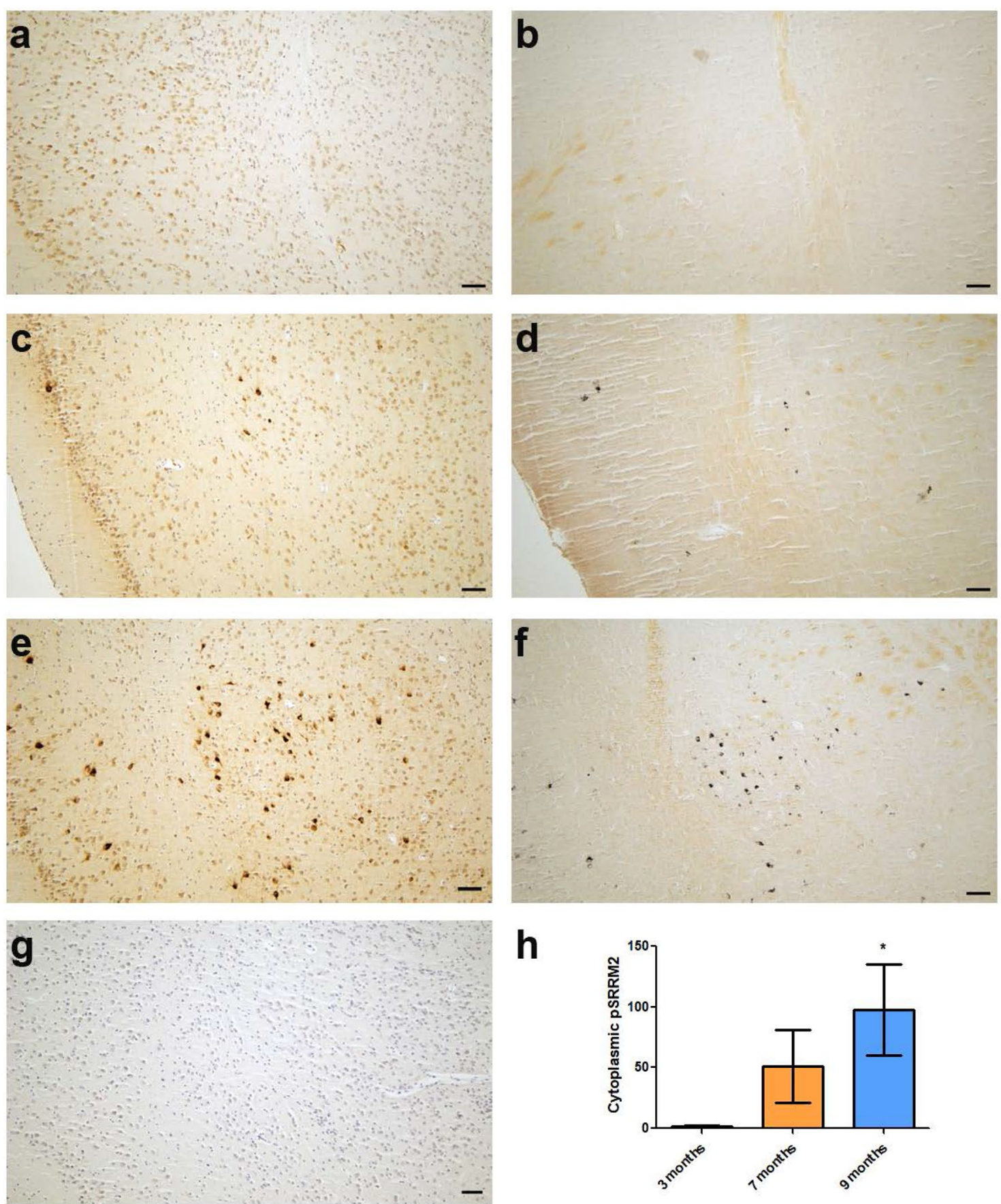

Fig. 2 Abnormal pSRRM2 mis-localization occurs in a transgenic mouse model of tauopathy. Immunostaining with SC-35 antibody (a, c, e, $\mathbf{g}$ ) demonstrates that PSRRM2 is mis-localized to the neuronal cytoplasm in brain regions of PS19 mice where Gallyas positive NFTs (b, d, f) are prevalent. At three months, pSRRM2 appears as diffuse mild immunoreactivity in the cytoplasm (a) and there are no tangles (b). At seven months, a small number of Gallyas positive NFTs are present and neurons with robust cytoplasmic distribution are detectable in these same regions (c, $\mathbf{d})$. By nine months, PS19 mice with robust tangle burden display abnormal pSRRM2 cytoplasmic localization in a large number of neurons (e, $\mathbf{f}$ and quantified in $\mathbf{h})$. In contrast, pSRRM2 is not detectable in a nine-month-old non-Tg mouse brain $(\mathbf{g}) .\left({ }^{*} p=0.04\right.$ by two-tailed Student's $t$ test) Scale bars, $100 \mu \mathrm{m}$ 
soma in AD frontal cortex where we noted cytoplasmic pSRRM 2 in th $72 \%$ of AD cases. AD cases bearing cytoplasmic pSRRM2 exhibited a relatively younger age of AD onset (11 years earlier) as compared to cases lacking pSRRM2 mis-localization (Fig. 4a). Next, we examined the relationship between pSRRM2 mis-localization and frontal cortical pTau burden in AD, where we observed a significant increase in pTau abundance in cases with cytoplasmic mis-localization of pSRRM2 compared to cases with normal nuclear distribution (Fig. 4b). Finally, we assessed neurodegeneration through NeuN immunohistochemistry, where we observed increased neuronal loss in AD cases with aberrant cytoplasmic pSRRM2 (Fig. 4c). Taken together, these results demonstrate that cytoplasmic distribution of PSRRM2 appears to coincide with exacerbated AD clinical onset and neuropathological severity.

\section{Discussion \\ Pathological tau drives nuclear speckle scaffold protein mislocalization to the cytoplasm}

We observed ectopic accumulation of the nuclear speckle scaffold protein SRRM2 in the cytoplasm in $\mathrm{AD}$, and PSRRM2 + deposits overlap with the neurofibrillary tangle pathology in AD. To investigate the relationship between pathological tau and ectopic SRRM2, we employed robust animal models of pathological tau deposition and found that PSRRM2 became progressively recruited to the cytoplasm as pathological tau deposition increased. In addition, pathological tau and pSRRM2 + deposits co-localize within the neuronal soma and remain in close proximity within tangle bearing neurons. Taken together, these findings support a tauopathy cascade model whereby $A \beta$, aging, or some other stimulus triggers pathological tau deposition in the cytoplasm, which recruits PSRRM2 to the fibrillar tau deposits leading to dysfunction of nuclear speckles (Fig. 5a).

\section{RNA-binding proteins modulate tauopathy}

We previously identified RNA binding proteins that reside in nuclear speckles, including sut-1, sut-2/ MSUT2, and parn-2/TOE1. Examination of genes required for tau pathology-driven neurodegeneration in C. elegans uncovered suppressor of tauopathy 1 (sut-1), a nuclear speckle resident protein whose loss of function prevents tau-mediated neurodegeneration; sut-1 functions in speckles and plays a role in $C$. elegans trans-splicing [14]. The same genetic approach uncovered sut-2 as a genetic suppressor of tauopathy [16], and subsequent translational studies revealed that the mammalian homolog of sut-2 (MSUT2) also resides in nuclear speckles and plays a critical role in tau aggregation and neurodegeneration in mice, human cells, and AD brain tissue [19, 25]. Recent studies of other nuclear speckle resident proteins revealed that the nuclear speckle resident RNA nucleases parn-1/ PARN and parn-2/TOE1 play distinct roles in tau toxicity [15]. Contemporaneous work from other laboratories has also implicated RNA-binding proteins in tauopathy, including Musashi (MSI) and T-cell intracellular antigen 1 (TIA1); while they have divergent RNAbinding functions, both TIA1 and MSI co-localize with tau-containing cytoplasmic lesions and modulate tau aggregation and concomitant tauopathy phenotypes in model systems [30-33].

\section{SRRM2 phosphorylation and mis-localization occurs in AD}

Tanaka and colleagues demonstrated that abnormally localized SRRM2 occurs in both AD and animal models of A $\beta$ deposition, driving aberrant splicing [22]. They further reported that phosphorylation of SRRM2 at pS1068 stimulates SRRM2 transit from the nucleus to cytoplasm, and hypothesized that ER stress activation of ERK1/2 drives pSRRM2 phosphorylation [22]. Here, we show that pathological tau, in the absence of $\mathrm{A} \beta$, can provoke pSRRM2 accumulation in the cytoplasm in mouse models, consistent with our observation that abnormal pSRRM2 deposition coincides with severity of AD tau pathology. Recent work has also demonstrated that pathological tau drives ER stress in both animal models [34-36] and in AD [37-40]. We hypothesize a cascade where pathological tau provokes pSRRM2 mislocalization through an ER stress and ERK1/2 mediated pathway resulting in aberrant splicing and ultimately neurodegeneration (Fig. 5b).

\footnotetext{
(See figure on next page.)

Fig. 3 pSRRM2 co-localizes with pathological tau in AD. a pSRRM2 (Red) is localized to the nucleus and pTau (pS422-Green) is cytoplasmic in cognitively normal elderly controls; visible overlapping signal is visualized as yellow (Pearson Coefficient of Colocalization $=0.017$ ), (Panel image scale bar = 100um; inset scale bar $=25 \mathrm{um}$ ). b pSRRM2 (Red) relocalizes to the cytoplasm and colocalizes with pTau (Green), as visualized in yellow in AD patients (Pearson Coefficient of Colocalization= 0.99). (Panel image scale bar =100um; inset scale bar = 10um). c Proximity Ligation Assay imaging between PSRRM2 and pTau. Top: Panel image and inset imaging of PLA colocalization in a cognitively normal elderly control donor shows minimal cytoplasmic colocalization (Panel image scale bar =100um; inset scale bar =10um). Bottom: Panel image and inset imaging of PLA colocalization in an AD donor show significant colocalization in the cytoplasm (Panel image scale bar $=100$ um; inset scale bar $=10$ um)
} 
a

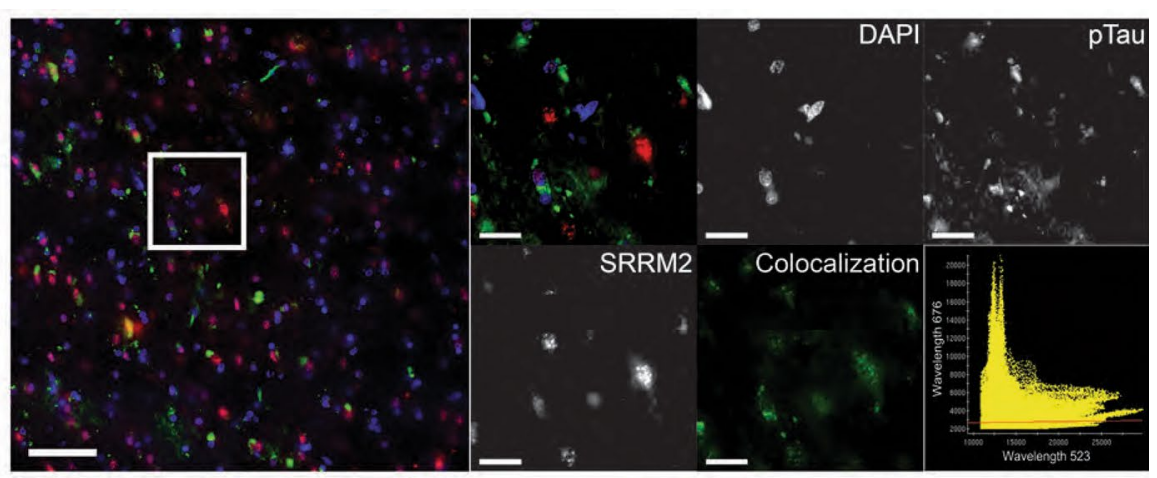

b

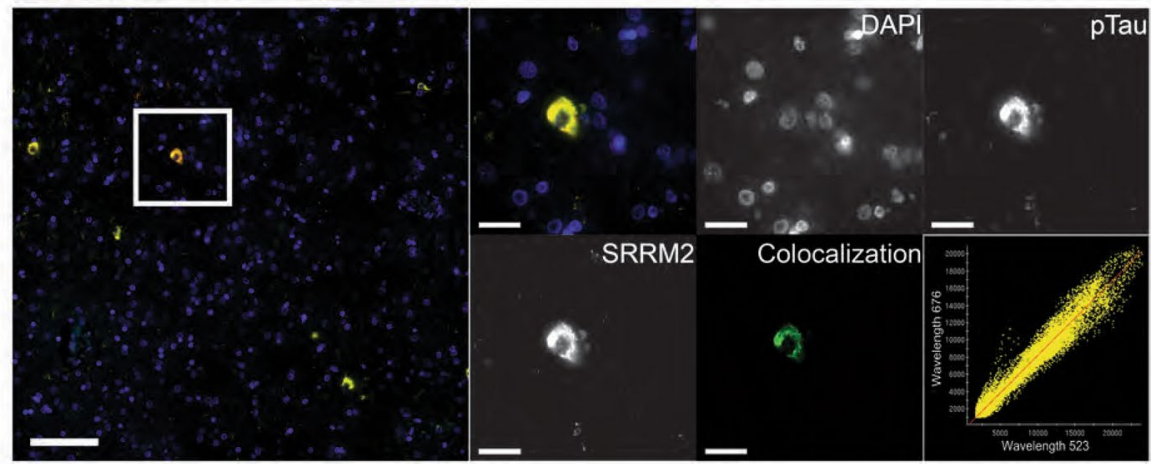

c
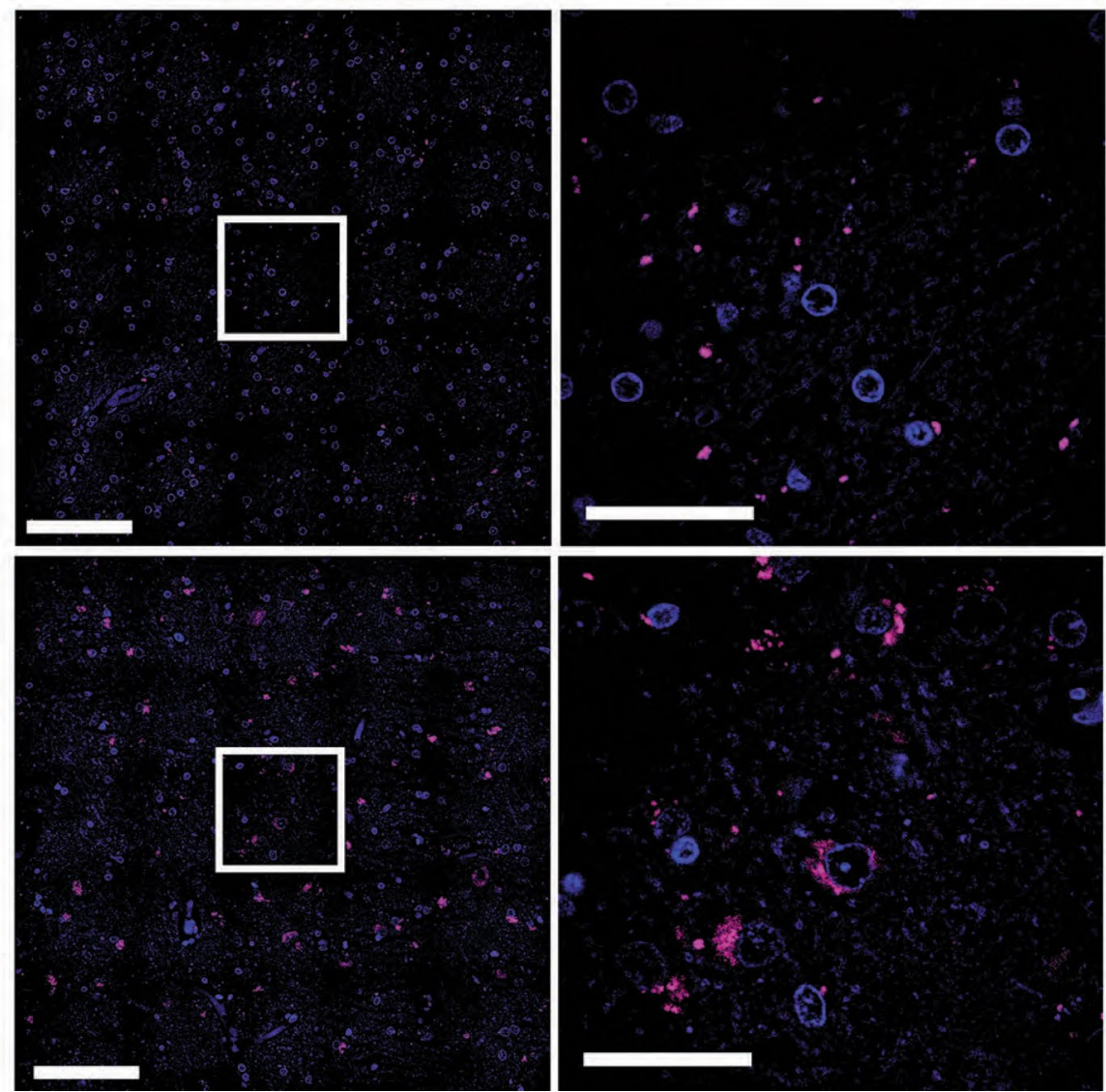

Fig. 3 (See legend on previous page.) 
Table 3 Case IHC data summary

\begin{tabular}{|c|c|c|c|c|}
\hline Case \# & Dx & pSRRM2 & MSUT2 & AT180 \\
\hline 10 & $A D$ & Cytoplasmic & Depleted & +++ \\
\hline 6 & $A D$ & Cytoplasmic & Depleted & +++ \\
\hline 8 & $A D$ & Cytoplasmic & Depleted & +++ \\
\hline 9 & $A D$ & Cytoplasmic & Depleted & +++ \\
\hline 16 & $A D$ & Cytoplasmic & Positive & +++ \\
\hline 5 & $A D$ & Cytoplasmic & Depleted & +++ \\
\hline 1 & $A D$ & Cytoplasmic & Depleted & +++ \\
\hline 2 & $A D$ & Cytoplasmic & Depleted & +++ \\
\hline 3 & $A D$ & Cytoplasmic & Depleted & +++ \\
\hline 7 & $A D$ & Cytoplasmic & Depleted & ++ \\
\hline 13 & $A D$ & Cytoplasmic & Positive & ++ \\
\hline 11 & $A D$ & Cytoplasmic & Depleted & ++ \\
\hline 4 & $A D$ & Cytoplasmic & Depleted & ++ \\
\hline 12 & $A D$ & Cytoplasmic & Positive & ++ \\
\hline 18 & $A D$ & Mixed & Depleted & +++ \\
\hline 17 & $A D$ & Mixed & Depleted & +++ \\
\hline 20 & $A D$ & Mixed & Positive & ++ \\
\hline 19 & $A D$ & Mixed & Depleted & + \\
\hline 28 & $A D$ & Nuclear & Positive & ++ \\
\hline 23 & $A D$ & Nuclear & Positive & ++ \\
\hline 29 & $A D$ & Nuclear & Positive & + \\
\hline 24 & $A D$ & Nuclear & Positive & + \\
\hline 22 & $A D$ & Nuclear & Positive & + \\
\hline 21 & $A D$ & Nuclear & Positive & + \\
\hline 26 & $A D$ & Nuclear & Positive & + \\
\hline 27 & $A D$ & Nuclear & Positive & + \\
\hline
\end{tabular}

+ , mild; ++ , moderate; +++ , robust AT180 $p$-tau accumulation

\section{Tau aggregates as RNA-protein assemblies associated with nuclear speckles}

Several studies have shown that tau immunopurifies with several RNA-binding proteins [41, 42], and recent work has nominated nuclear speckles as a participant in tauopathies through the scaffold protein SRRM2. Lester and colleagues showed that tau deposits purified from model systems, including mice and human cells, contain many RNAs and are highly enriched for small nuclear and small nucleolar RNAs (snRNAs and
snoRNAs) [7]. These findings are consistent with previous work showing that tau aggregates in brain are typically RNA-positive [43], and suggest pathological properties for nuclear tau [42, 44-46], as Lester and colleagues speculate pathological tau may be seeded by RNA into nuclear aggregates in human tauopathy disorders. In model systems this may be particularly relevant, as tau truncated species accumulate to high levels in many models, and tau fragments readily relocalize to the nucleus in some cellular systems [47]. Investigation of a small number of human tauopathy cases demonstrated mislocalization of SRRM2 in AD, but did not document the presence of nuclear tau/RNA assemblies [7]. Here, we confirm nuclear clearance and cytoplasmic accumulation of pSRRM2 in a larger $\mathrm{AD}$ cohort, and demonstrate variability in pSRRM2 related pathologic changes in the frontal cortex of $\mathrm{AD}$ cases. In sum, these studies highlight the dysfunction of nuclear speckles in AD. To further understand the mechanistic disease relevance of nuclear speckle disruption in $\mathrm{AD}$, transcriptomic and proteomic characterization of pSRRM2 + cytoplasmic deposits in AD should be prioritized in future work, and comparison of SRRM2 + deposits between AD brain and model systems may be critical to understand possible disease mechanisms.

\section{Tau mediates neurodegeneration through nuclear RNA processing defects}

Multiple studies have demonstrated that tau neuropathology drives neurodegeneration by causing dysfunction of nuclear RNA processing events (reviewed in [48]). Recently, tau aggregates have been shown to disrupt the nuclear pore complex, blocking export of mRNAs via nuclear depletion and co-aggregation of tau with the disordered region of Nup98 [49]. This molecular phenotype is reminiscent of the findings reported here for PSRRM2, which is co-deposited with pathological tau. Subsequent related work in model systems has shown clear evidence for mRNA accumulation within nuclear invaginations caused by pathological tau, further supporting disruption of RNA trafficking as a critical pathological consequence of

\footnotetext{
(See figure on next page.)

Fig. 4 pSRRM2 mis-localization in AD associates with disease severity. Cytoplasmic pSRRM2 accumulation in AD brain is associated with a more aggressive disease progression. a AD donors with predominately cytoplasmic PSRRM2 in postmortem frontal cortex $(n=20)$ had an earlier age of disease onset compared to those with primarily nuclear pSRRM 2 distribution $(n=9)(* * p=0.0042$ by two-tailed Student's $t$ test). b Representative brain sections from frontal cortex of an AD donor with normal nuclear PSRRM2 distribution (top) compared to an AD donor with abnormal cytoplasmic accumulation of pSRRM2 (bottom) stained with the anti-phosphorylated tau antibody AT180. Brain tissue from cases with cytoplasmic pSRRM2 exhibited more pathological tau. Densitometry analysis of AT180-positive reactivity in AD cases with nuclear $(n=8)$ or cytoplasmic $(n=19)$ pSRRM2 (*** $p=0.0002$ by two-tailed Student's $t$ test). $\mathbf{c}$ Representative brain sections from postmortem brain frontal cortex of an AD donor with normal nuclear pSRRM2 distribution (top) compared to an AD donor with abnormal cytoplasmic accumulation of pSRRM2 (bottom) stained with the neuronal marker NeuN. Brain tissue from cases with cytoplasmic PSRRM2 exhibited decreased NeuN immunoreactivity (indicative of more neuronal loss). Densitometry analysis of NeuN-positive reactivity in AD cases with nuclear $(n=9)$ or cytoplasmic $(n=18) p S R R M 2\left({ }^{* *} p=0.0025\right.$ by two-tailed Student's t test). Scale bars, $250 \mu \mathrm{m}$
} 


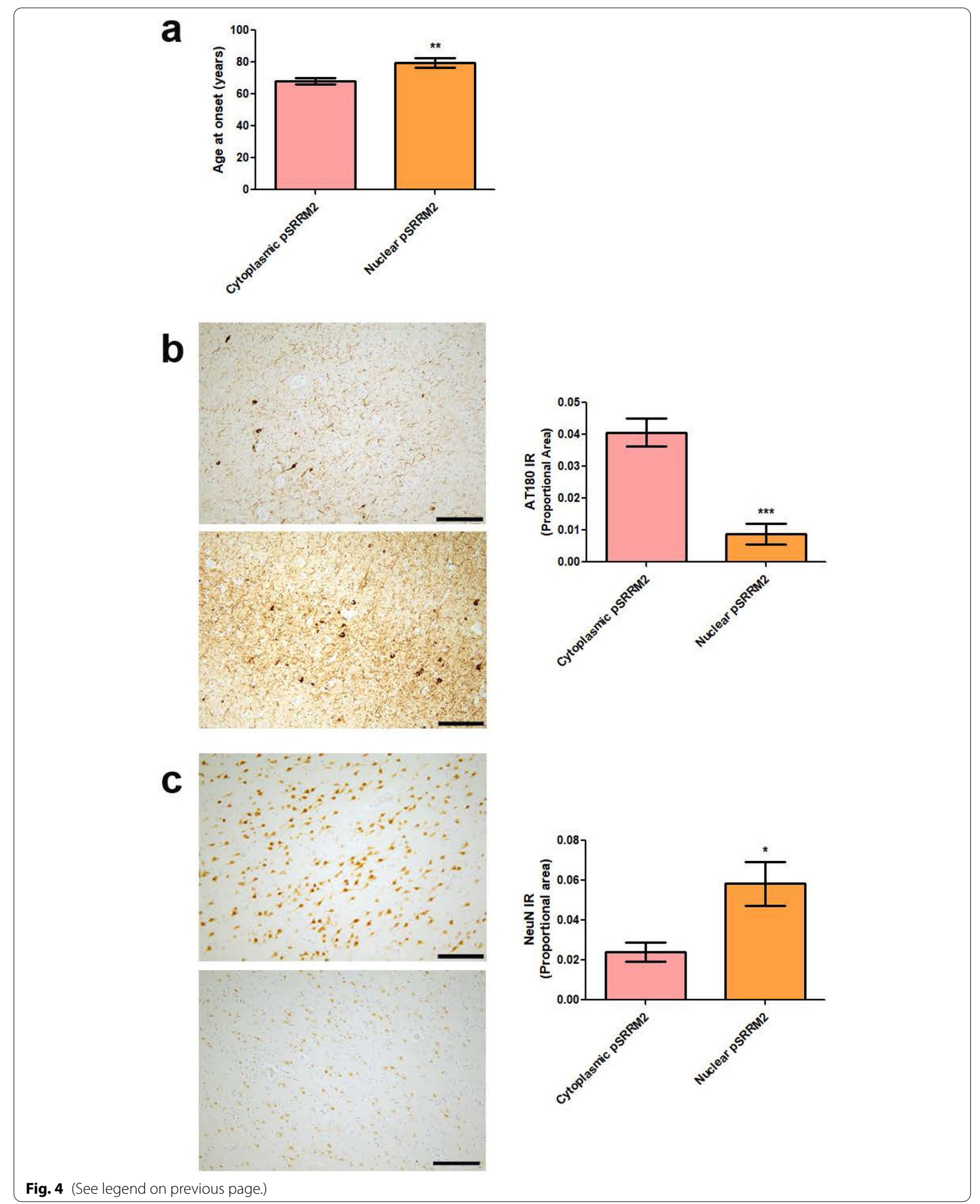




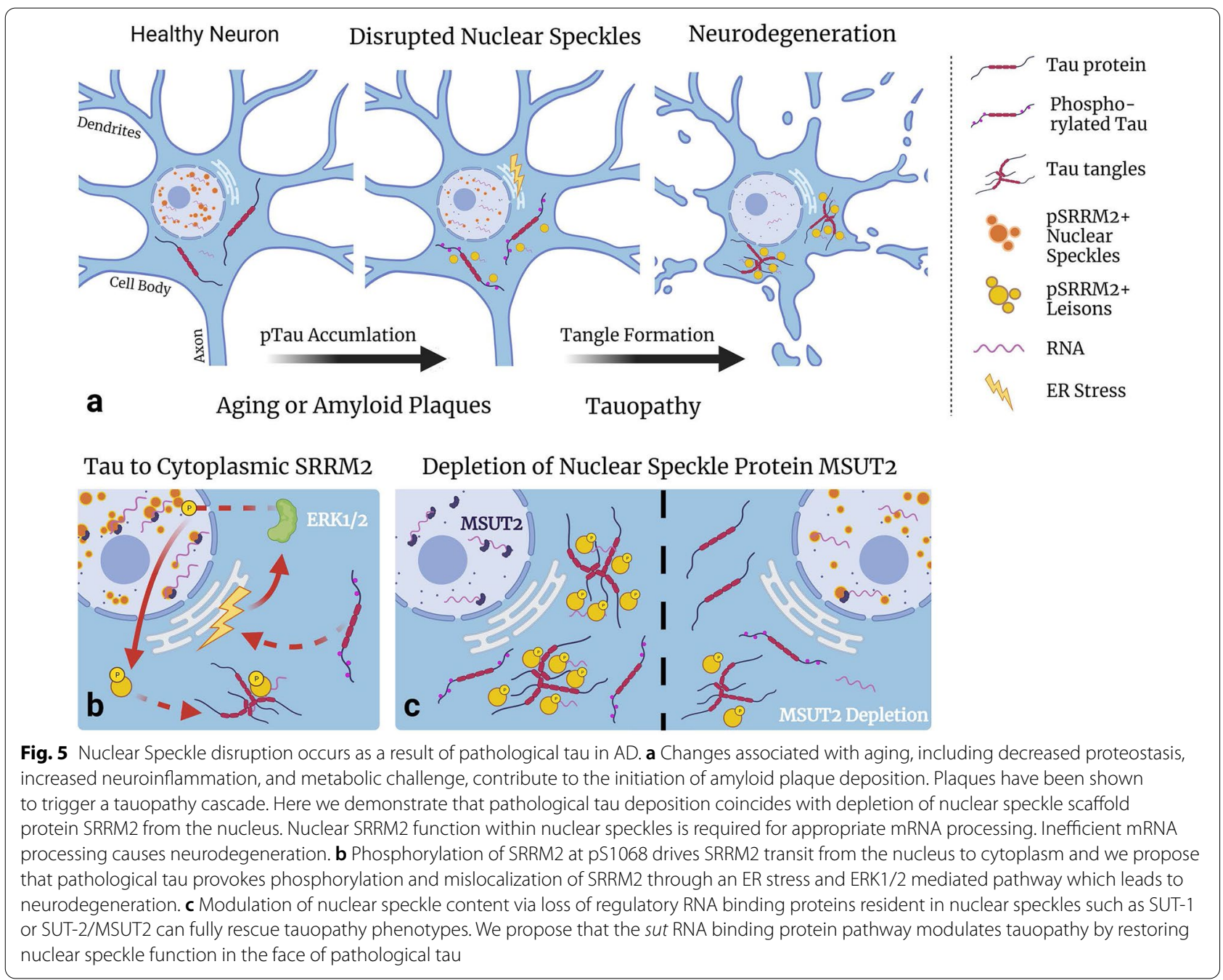

tau aggregation [6]. Other studies have implicated defects in mRNA splicing as a critical nuclear process disrupted in AD specifically nominating disruption of $U 1$ snRNP via mislocalization of the RNA binding protein U1-70 K [42, $50,51]$. Further, tau mediated spliceosome dysfunction has been hypothesized as a trigger of cryptic RNA splicing and consequent neurodegeneration in $\mathrm{AD}$ [12].

\section{Tau mediated neurodegeneration can be modulated by altering nuclear speckle contents}

A recurring theme in tau mediated neurodegeneration is the depletion of an essential RNA-binding protein from the nucleus as a result of co-aggregation with cytoplasmic pathological tau. We reiterate this has been shown to occur for pSRRM2 (this study \& [7]), Nup98 [49], and U1-70 k [42, 50, 51]; the loss of function for any one of these three critical proteins likely dooms a neuron to degeneration. However, previous genetic studies have demonstrated rescue of tauopathy phenotypes by loss of function mutations in RNA-binding proteins. Modulation of nuclear speckle content via loss of regulatory RNA-binding proteins resident in nuclear speckles, such as SUT-1 or SUT-2/MSUT2, can fully rescue tauopathy phenotypes in model systems including tau transgenic $C$. elegans, human cells and mouse brains $[16,19,25]$. We hypothesize that the sut RNA-binding protein pathway modulates tauopathy by restoring nuclear speckle function in the face of pathological tau (Fig. 5c).

The findings of our work, combined with the evidence from the literature, support the hypothesis that changes in the content of nuclear speckles contributes to tauopathy mediated neurodegeneration in AD. Tau-mediated neurodegeneration can be rescued in animal models by altering the content of nuclear speckles, for instance by targeting MSUT2 or related proteins [19]. Examination of the transcriptome and proteome of SRRM2+/tau deposits and nuclear speckles in $\mathrm{AD}$ remain important 
future directions for our work investigating the molecular mechanisms of tauopathy disorders and will inform future molecular dissection of tau pathobiology.

\section{Supplementary Information}

The online version contains supplementary material available at https://doi. org/10.1186/s40478-021-01219-1.

Additional file 1: Fig. 1. Tau4Rtg2652 mice exhibit a milder but disrupted nuclear speckle staining pattern for pSRRM2. Immunostaining with SC-35 antibody demonstrates that PSRRM2 is mis-localized in hippocampal CA3 neurons of a four-month-old Tau4Rtg2652 mouse (b) and appears as diffuse cytoplasmic staining. No immunoreactivity is detectable in a four month old non-Tg mouse brain (a). Scale bars, $50 \mu \mathrm{m}$.

\section{Acknowledgements}

We thank the reviewers for helpful comments and suggestions. We thank Roy Parker and Evan Lester for discussing the role of nuclear speckles in tauopathy prior to publication of their recent manuscript [7]. We thank Allison Beller and Erica Melief for administrative support, and Elaine Loomis, Linda Robinson, Aleen Saxton, and Kim Howard for outstanding technical assistance. We thank Manuela Neumann, Peter Davies and Virginia Lee for antibodies. We thank Rebecca Kow and Nicole Liachko for reading and commenting on the manuscript. Finally, we thank research brain donors and their families, without whom this work would be impossible.

\section{Authors' contributions}

PJM conceptualized the study, conducted experiments, analyzed data, wrote the first draft manuscript, generated graphics, and co-authored the manuscript; TJS conducted experiments, analyzed data, generated graphics, and co-authored the manuscript. MB conducted experiments, analyzed data, and co-authored the manuscript; BKM conducted experiments and co-authored the manuscript; RJE analyzed data, generated graphics, and co-authored the manuscript; $\mathrm{NH}$ conducted experiments, and co-authored the manuscript; JW conducted experiments, secured regulatory approval, and co-authored the manuscript; CSL characterized brain tissue, analyzed data, and co-authored the manuscript; CDK characterized brain tissue, analyzed data, and coauthored the manuscript. BCK conceptualized the study, secured funding, secured regulatory approval, provided project supervision, analyzed data, wrote the first draft manuscript, generated graphics, and co-authored the manuscript. All authors read and approved the final manuscript.

\section{Funding}

This work was supported by a Grant from the Department of Veterans Affairs and National Institutes of Health [RF1 AG055474 and R01 NS064131 to B.C.K], K08 AG065426 to C.S.L., the UW ADRC [P30 AG0066509], the ACT study [(U01 AG006781] and the Nancy and Buster Alvord Endowment to C.D.K.

\section{Data availability}

The datasets generated and analyzed during this study are included in this published article and its supplementary information files, or are available from the corresponding author on reasonable request.

\section{Declarations}

\section{Ethics approval and consent to participate}

Only deceased de-identified autopsy specimens obtained from the University of Washington Alzheimer's Disease Research Center were used for this study. Animal ethics approval was granted by the VA Puget Sound Institutional Animal Use Committee.

\section{Consent for publication}

Not applicable.

\section{Competing interests}

The authors declare that they have no competing interests.

\section{Author details}

${ }^{1}$ Geriatrics Research Education and Clinical Center, Veterans Affairs Puget Sound Health Care System, S182, 1660 South Columbian Way, Seattle, WA 98108, USA. ${ }^{2}$ Department of Psychiatry and Behavioral Sciences, University of Washington, Seattle, WA 98195, USA. ${ }^{3}$ Graduate Program in Neuroscience, University of Washington, Seattle, WA 98195, USA. ${ }^{4}$ Department of Laboratory Medicine and Pathology, University of Washington, Seattle, WA 98195, USA. ${ }^{5}$ Division of Gerontology and Geriatric Medicine, Department of Medicine, University of Washington, Seattle, WA 98104, USA.

Received: 16 June 2021 Accepted: 17 June 2021

Published online: 29 June 2021

\section{References}

1. Clark LN, Poorkaj P, Wszolek Z, Geschwind DH, Nasreddine ZS, Miller B, Li D, Payami H, Awert F, Markopoulou K et al (1998) Pathogenic implications of mutations in the tau gene in pallido-ponto-nigral degeneration and related neurodegenerative disorders linked to chromosome 17. Proc Natl Acad Sci USA 95:13103-13107

2. Hutton M, Lendon CL, Rizzu P, Baker M, Froelich S, Houlden H, PickeringBrown S, Chakraverty S, Isaacs A, Grover A et al (1998) Association of missense and 5 '-splice-site mutations in tau with the inherited dementia FTDP-17. Nature 393:702-705

3. Spillantini MG, Murrell JR, Goedert M, Farlow MR, Klug A, Ghetti B (1998) Mutation in the tau gene in familial multiple system tauopathy with presenile dementia. Proc Natl Acad Sci USA 95:7737-7741

4. Bierer LM, Hof PR, Purohit DP, Carlin L, Schmeidler J, Davis KL, Perl DP (1995) Neocortical neurofibrillary tangles correlate with dementia severity in Alzheimer's disease. Arch Neurol 52:81-88

5. Bai B, Hales CM, Chen PC, Gozal Y, Dammer EB, Fritz JJ, Wang X, Xia Q, Duong DM, Street C et al (2013) U1 small nuclear ribonucleoprotein complex and RNA splicing alterations in Alzheimer's disease. Proc Natl Acad Sci USA 110:16562-16567. https://doi.org/10.1073/pnas.1310249110

6. Cornelison GL, Levy SA, Jenson T, Frost B (2019) Tau-induced nuclear envelope invagination causes a toxic accumulation of mRNA in Drosophila. Aging Cell 18:e12847. https://doi.org/10.1111/acel.12847

7. Lester E, Ooi FK, Bakkar N, Ayers J, Woerman AL, Wheeler J, Bowser R, Carlson GA, Prusiner SB, Parker R (2021) Tau aggregates are RNA-protein assemblies that mislocalize multiple nuclear speckle components. Neuron. https://doi.org/10.1016/j.neuron.2021.03.026

8. Montalbano M, McAllen S, Puangmalai N, Sengupta U, Bhatt N, Johnson OD, Kharas MG, Kayed R (2020) RNA-binding proteins Musashi and tau soluble aggregates initiate nuclear dysfunction. Nat Commun 11:4305. https://doi.org/10.1038/s41467-020-18022-6

9. Dinkel PD, Holden MR, Matin N, Margittai M (2015) RNA binds to tau fibrils and sustains template-assisted growth. Biochemistry 54:4731-4740. https://doi.org/10.1021/acs.biochem.5b00453

10. Kampers T, Friedhoff P, Biernat J, Mandelkow EM (1996) RNA stimulates aggregation of microtubule-associated protein tau into Alzheimer-like paired helical filaments. FEBS Lett 399:344-349

11. Zhang X, Lin Y, Eschmann NA, Zhou H, Rauch JN, Hernandez I, Guzman E, Kosik KS, Han S (2017) RNA stores tau reversibly in complex coacervates. PLoS Biol 15:e2002183. https://doi.org/10.1371/journal.pbio.2002183

12. Hsieh YC, Guo C, Yalamanchili HK, Abreha M, Al-Ouran R, Li Y, Dammer EB, Lah JJ, Levey Al, Bennett DA et al (2019) Tau-mediated disruption of the spliceosome triggers cryptic RNA splicing and neurodegeneration in Alzheimer's disease. Cell Rep 29(301):316. https://doi.org/10.1016/j.celrep. 2019.08.104

13. Kraemer BC, Schellenberg GD (2007) SUT-1 enables tau-induced neurotoxicity in C. elegans. Hum Mol Genet 16:1959-1971

14. MacMorris M, Kumar M, Lasda E, Larsen A, Kraemer B, Blumenthal T (2007) A novel family of $C$. elegans snRNPs contains proteins associated with trans-splicing. RNA 13:511-520

15. Kow RL, Strovas TJ, McMillan PJ, Jacobi AM, Behlke MA, Saxton AD, Latimer CS, Keene CD, Kraemer BC (2021) Distinct Poly(A) nucleases have differential impact on sut-2 dependent tauopathy phenotypes. Neurobiol Dis 147:105148. https://doi.org/10.1016/j.nbd.2020.105148 
16. Guthrie CR, Schellenberg GD, Kraemer BC (2009) SUT-2 potentiates tau-induced neurotoxicity in Caenorhabditis elegans. Hum Mol Genet 18:1825-1838. https://doi.org/10.1093/hmg/ddp099

17. Spector DL, Lamond Al (2011) Nuclear speckles. Cold Spring Harb Perspect Biol. https://doi.org/10.1101/cshperspect.a000646

18. Strom AR, Brangwynne CP (2019) The liquid nucleome-phase transitions in the nucleus at a glance. J Cell Sci. https://doi.org/10.1242/jcs.235093

19. Wheeler JM, McMillan P, Strovas TJ, Liachko NF, Amlie-Wolf A, Kow RL, Klein RL, Szot P, Robinson L, Guthrie C et al (2019) Activity of the poly(A) binding protein MSUT2 determines susceptibility to pathological tau in the mammalian brain. Sci Transl Med. https://doi.org/10.1126/scitrans/m ed.aao6545

20. Luna-Munoz J, Garcia-Sierra F, Falcon V, Menendez I, Chavez-Macias L, Mena R (2005) Regional conformational change involving phosphorylation of tau protein at the Thr231, precedes the structural change detected by Alz-50 antibody in Alzheimer's disease. J Alzheimers Dis 8:29-41

21. Weaver CL, Espinoza M, Kress Y, Davies P (2000) Conformational change as one of the earliest alterations of tan in Alzheimer's disease. Neurobiol Aging 21:719-727

22. Tanaka H, Kondo K, Chen X, Homma H, Tagawa K, Kerever A, Aoki S, Saito T, Saido T, Muramatsu SI et al (2018) The intellectual disability gene PQBP1 rescues Alzheimer's disease pathology. Mol Psychiatry 23:20902110. https://doi.org/10.1038/s41380-018-0253-8

23. Yoshiyama Y, Higuchi M, Zhang B, Huang SM, Iwata N, Saido TC, Maeda J, Suhara T, Trojanowski JQ, Lee VM (2007) Synapse loss and microglial activation precede tangles in a P301S tauopathy mouse model. Neuron 53:337-351

24. Fu XD, Maniatis T (1990) Factor required for mammalian spliceosome assembly is localized to discrete regions in the nucleus. Nature 343:437441. https://doi.org/10.1038/343437a0

25. Guthrie CR, Greenup L, Leverenz JB, Kraemer BC (2011) MSUT2 is a determinant of susceptibility to tau neurotoxicity. Hum Mol Genet 20:1989-1999. https://doi.org/10.1093/hmg/ddr079

26. Ilik IA, Malszycki M, Lubke AK, Schade C, Meierhofer D, Aktas T (2020) SON and SRRM2 are essential for nuclear speckle formation. Elife. https://doi. org/10.7554/eLife.60579

27. Blencowe BJ, Bauren G, Eldridge AG, Issner R, Nickerson JA, Rosonina E, Sharp PA (2000) The SRm160/300 splicing coactivator subunits. RNA 6:111-120. https://doi.org/10.1017/s1355838200991982

28. Khanna M, Van Bakel H, Tang X, Calarco JA, Babak T, Guo G, Emili A, Greenblatt JF, Hughes TR, Krogan NJ et al (2009) A systematic characterization of CWC21, the yeast ortholog of the human spliceosomal protein SRm300. RNA 15:2174-2185. https://doi.org/10.1261/rna.1790509

29. Fontrodona L, Porta-de-la-Riva M, Moran T, Niu W, Diaz M, AristizabalCorrales D, Villanueva A, Schwartz S Jr, Reinke V, Ceron J (2013) RSR-2, the Caenorhabditis elegans ortholog of human spliceosomal component SRm300/SRRM2, regulates development by influencing the transcriptional machinery. PLoS Genet 9:e1003543. https://doi.org/10.1371/journ al.pgen.1003543

30. Ash PEA, Lei S, Shattuck J, Boudeau S, Carlomagno Y, Medalla M, Mashimo BL, Socorro G, Al-Mohanna LFA, Jiang L et al (2021) TIA1 potentiates tau phase separation and promotes generation of toxic oligomeric tau. Proc Natl Acad Sci USA. https://doi.org/10.1073/pnas.2014188118

31. Jiang $L$, Ash PEA, Maziuk BF, Ballance HI, Boudeau S, Abdullatif AA, Orlando M, Petrucelli L, Ikezu T, Wolozin B (2019) TIA1 regulates the generation and response to toxic tau oligomers. Acta Neuropathol 137:259-277. https://doi.org/10.1007/s00401-018-1937-5

32. Maziuk BF, Apicco DJ, Cruz AL, Jiang L, Ash PEA, da Rocha EL, Zhang C, Yu WH, Leszyk J, Abisambra JF et al (2018) RNA binding proteins co-localize with small tau inclusions in tauopathy. Acta Neuropathol Commun 6:71. https://doi.org/10.1186/s40478-018-0574-5

33. Sengupta U, Montalbano M, McAllen S, Minuesa G, Kharas M, Kayed R (2018) Formation of toxic oligomeric assemblies of RNA-binding protein: musashi in Alzheimer's disease. Acta Neuropathol Commun 6:113. https://doi.org/10.1186/s40478-018-0615-0

34. Abisambra JF, Jinwal UK, Blair LJ, O'Leary JC 3rd, Li Q, Brady S, Wang L, Guidi CE, Zhang B, Nordhues BA et al (2013) Tau accumulation activates the unfolded protein response by impairing endoplasmic reticulumassociated degradation. J Neurosci 33:9498-9507. https://doi.org/10. 1523/JNEUROSCI.5397-12.2013
35. Loewen CA, Feany MB (2010) The unfolded protein response protects from tau neurotoxicity in vivo. PLoS ONE. https://doi.org/10.1371/journal. pone.0013084

36. Waldherr SM, Strovas TJ, Vadset TM, Liachko NF, Kraemer BC (2019) Constitutive XBP-1s-mediated activation of the endoplasmic reticulum unfolded protein response protects against pathological tau. Nat Commun (in press)

37. Hoozemans JJ, Stieler J, van Haastert ES, Veerhuis R, Rozemuller AJ, Baas F, Eikelenboom P, Arendt T, Scheper W (2006) The unfolded protein response affects neuronal cell cycle protein expression: Implications for Alzheimer's disease pathogenesis. Exp Gerontol 41:380-386

38. Hoozemans JJ, van Haastert ES, Nijholt DA, Rozemuller AJ, Eikelenboom P, Scheper W (2009) The unfolded protein response is activated in pretangle neurons in Alzheimer's disease hippocampus. Am J Pathol 174:12411251. https://doi.org/10.2353/ajpath.2009.080814

39. Nijholt DA, van Haastert ES, Rozemuller AJ, Scheper W, Hoozemans JJ (2012) The unfolded protein response is associated with early tau pathology in the hippocampus of tauopathies. J Pathol 226:693-702. https:// doi.org/10.1002/path.3969

40. Scheper W, Hoozemans JJ, Hoogenraad CC, Rozemuller AJ, Eikelenboom P, Baas F (2007) Rab6 is increased in Alzheimer's disease brain and correlates with endoplasmic reticulum stress. Neuropathol Appl Neurobiol 33:523-532. https://doi.org/10.1111/j.1365-2990.2007.00846.x

41. Guo Q, Dammer EB, Zhou M, Kundinger SR, Gearing M, Lah JJ, Levey Al, Shulman JM, Seyfried NT (2021) Targeted quantification of detergentinsoluble RNA-binding proteins in human brain reveals stage and disease specific co-aggregation in Alzheimer's disease. Front Mol Neurosci 14:623659. https://doi.org/10.3389/fnmol.2021.623659

42. Hales CM, Dammer EB, Deng Q, Duong DM, Gearing M, Troncoso JC, Thambisetty M, Lah JJ, Shulman JM, Levey Al et al (2016) Changes in the detergent-insoluble brain proteome linked to amyloid and tau in Alzheimer's Disease progression. Proteomics 16:3042-3053. https://doi.org/10. 1002/pmic.201600057

43. Ginsberg SD, Crino PB, Lee VM, Eberwine JH, Trojanowski JQ (1997) Sequestration of RNA in Alzheimer's disease neurofibrillary tangles and senile plaques. Ann Neurol 41:200-209. https://doi.org/10.1002/ana. 410410211

44. Brady RM, Zinkowski RP, Binder LI (1995) Presence of tau in isolated nuclei from human brain. Neurobiol Aging 16:479-486. https://doi.org/10.1016/ 0197-4580(95)00023-8

45. Bukar Maina M, Al-Hilaly YK, Serpell LC (2016) Nuclear tau and its potential role in Alzheimer's disease. Biomolecules 6:9. https://doi.org/10.3390/ biom6010009

46. Loomis PA, Howard TH, Castleberry RP, Binder LI (1990) Identification of nuclear tau isoforms in human neuroblastoma cells. Proc Natl Acad Sci USA 87:8422-8426. https://doi.org/10.1073/pnas.87.21.8422

47. Preuss U, Biernat J, Mandelkow EM, Mandelkow E (1997) The "jaws" model of tau-microtubule interaction examined in $\mathrm{CHO}$ cells. J Cell Sci $110(\mathrm{Pt}$ 6):789-800

48. Diez L, Wegmann S (2020) Nuclear transport deficits in tau-related neurodegenerative diseases. Front Neurol 11:1056. https://doi.org/10.3389/ fneur.2020.01056

49. Eftekharzadeh B, Daigle JG, Kapinos LE, Coyne A, Schiantarelli J, Carlomagno Y, Cook C, Miller SJ, Dujardin S, Amaral AS et al (2018) Tau protein disrupts nucleocytoplasmic transport in Alzheimer's disease. Neuron 99(925):940. https://doi.org/10.1016/j.neuron.2018.07.039

50. Bishof I, Dammer EB, Duong DM, Kundinger SR, Gearing M, Lah JJ, Levey Al, Seyfried NT (2018) RNA-binding proteins with basic-acidic dipeptide (BAD) domains self-assemble and aggregate in Alzheimer's disease. J Biol Chem 293:11047-11066. https://doi.org/10.1074/jbc.RA118.001747

51. Hales CM, Dammer EB, Diner I, Yi H, Seyfried NT, Gearing M, Glass JD, Montine TJ, Levey Al, Lah JJ (2014) Aggregates of small nuclear ribonucleic acids (snRNAs) in Alzheimer's disease. Brain Pathol 24:344-351. https://doi.org/10.1111/bpa.12133

\section{Publisher's Note}

Springer Nature remains neutral with regard to jurisdictional claims in published maps and institutional affiliations. 